\title{
Capacitor Discharge Spot Welding of Aluminum, Part 2: Electrode Life Assessments
}

\author{
Duplicate electrode life tests were conducted using MFDC and \\ CD power supplies
}

BY J. E. GOULD, L. LINDAMOOD, J. MALPICA, P. LESTER, AND D. ZHU

\begin{abstract}
A major challenge for high-volume resistance spot welding of aluminum sheet is durability of the electrodes themselves. In production today, electrodes have total anticipated lives (including dressing) on the order of 1000 welds. This is largely related to the use of medium-frequency direct current (MFDC) power. The single-polarity orientation of MFDC welding results in excessive heating of one electrode (anode) and accelerated wear rates. Recently, technology employing capacitor discharge (CD) welding in conjunction with polarity switching has been developed. This work is the first effort in examining the response of resistance spot welding on aluminum sheet using this power source. Part 1 of this research (Ref. l) described basic process robustness in spot welding with CD power systems. Part 2 addresses electrode life response. Duplicate electrode life tests were completed for 2000 welds without failure. These results were related to the polarity switching and short time that produced balanced and minimized wear. Additional testing was done without the use of electrode-cooling water. A limited test ( 500 welds) largely paralleled the ones done with cooling, suggesting that long-term spot welding with polarity-switching CD power and no water was possible.
\end{abstract}

\section{KEYWORDS}

- Capacitor Discharge (CD) Welding • Electrode Life

- Spot Welding Aluminum

Aluminum usage in automotive construction is projected to increase for the foreseeable future (Ref. 2). One major challenge for this increased utilization has been application of conventional joining processes (Ref. 3). Traditionally, the dominant technology for sheet metal assembly in the automotive industry is resistance spot welding (Figs. 4, 5). A primary limitation to resistance spot welding aluminum sheet, however, has been electrode life (Ref. 1). A key contributing factor to electrode life challenges has been the implementation of medium-frequency direct current (MFDC) power supplies (Refs. 3, 6, 7).

MFDC power supplies provide unidirectional current to the workpiece. This unidirectional current is known to react with the Peltier voltages associated with the aluminumcopper contact surfaces (Ref. 6). These voltages either resist or promote current flow across the interface, and that either supports or discourages heat generation. As a result, the electrode with a Peltier voltage opposing the current flow experiences accelerated wear. Alternately, the opposing electrode shows relative stability (Refs. 6, 7).

The challenge is unique to direct current welding systems. Alternating current $(A C)$ systems demonstrate both balanced wear across the electrodes as well as a relatively extended life (Ref. 3). Polarity switching is seen as a method for improving electrode life performance on aluminum alloys. Recently, variants of MFDC power systems have been developed that provide polarity switching (Ref. 7). While initial electrode life advantages have been demonstrated, present systems do not have a sufficient current-delivery capability for widespread industrial application.

Resistance spot welding of aluminum using capacitor discharge (CD) power supplies has been well established for many decades (Refs. 8, 9). CD welding is a stored energy technology that allows delivery of very high currents of short duration. Recently, a patented technology was developed that allowed delivery of a CD-based current with reversed polarity on successive welds (Ref. 10). That technology has been built into a dedicated resistance spot welding system (Ref. 11). Polarity-switching-based CD technology is of interest for balancing wear across the electrodes and potentially improving electrode life.

The work described in this study has been conducted in two parts. The initial work, Part 1 , characterized basic resistance spot weldability when polarity-switched $C D$ power 


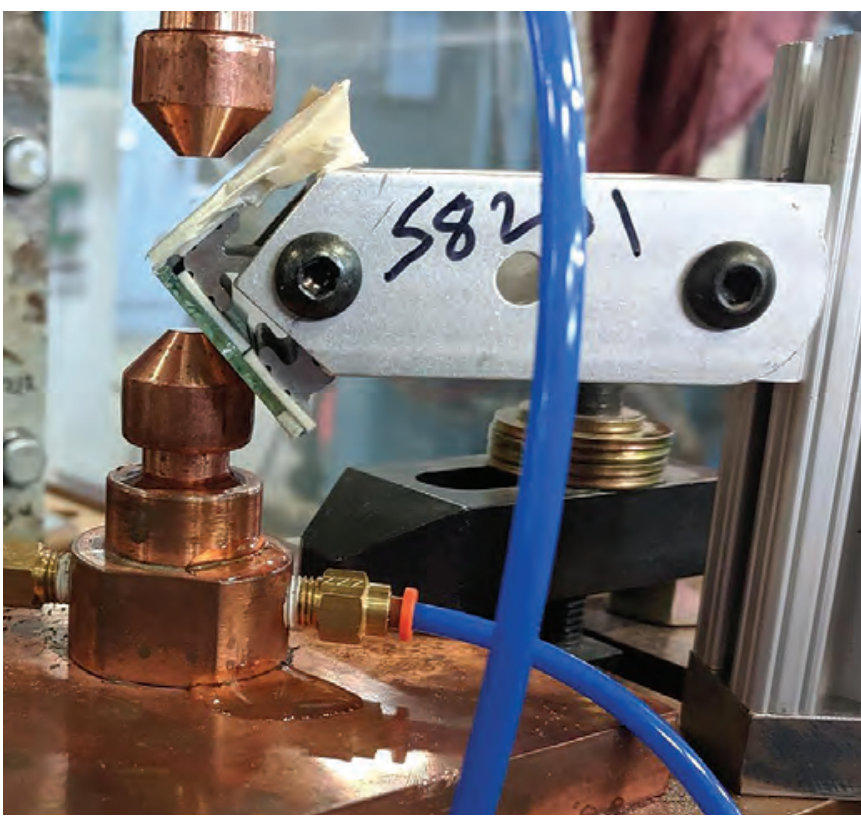

Fig. 1- Fixture retaining the mirrors for electrode face imaging. Note the orientation of the mirrors relative to the electrodes.

supplies were employed (Ref. 1). The results were directly compared to joints made using MFDC power. Those results showed that $C D$ welding provided enhanced current ranges (even when normalized to the expulsion current). In addition, the resulting nuggets showed reduced penetrations (internal porosity) and electrode indentation compared to MFDC welding. Furthermore, hardness variations within the weld were reduced when using $C D$ power. Tensile shear strengths also increased by nearly $500 \mathrm{~N}$ for the selected aluminum sheet. Lastly, CD-based resistance spot welding was found to be compatible with a selected adhesive.

This paper, Part 2, addresses actual electrode life testing by alternately using MFDC and CD power supplies. Replicate electrode life tests were done to monitor the variations in button size, electrode diameter, face morphology, and weld nugget characteristics. Tests using $C D$ welding were also replicated without cooling water applied to the electrodes.

\section{Experimental Procedures}

Work was done using 1-mm-thick 5182 aluminum sheet. The material has a composition of nominally $4-5 \% \mathrm{Mg}$ and $0.2-0.5 \% \mathrm{Mn}$ (Ref. 18). This is a work-hardened alloy with good corrosion resistance and is generally intended for nonexposed applications. Coupon dimensions for electrode life testing were taken from appropriate American Welding Society (AWS) standards (Ref. 12). The coupons measured 25 $\times 300 \mathrm{~mm}$. The rolling direction of the sheet was along the long axis of the coupons.

Welding was done on two pedestal-type resistance spot welding systems. These included the MFDC and polarityswitching CD systems described in Part 1 of this work (Ref. 1). The MFDC system included a 500-A Amada Miyachi inverter that was coupled with a 150-kVA transformer and a pedestal frame. This pedestal frame can provide welding loads up to roughly $12 \mathrm{kN}$. The CD system included a 1280 -

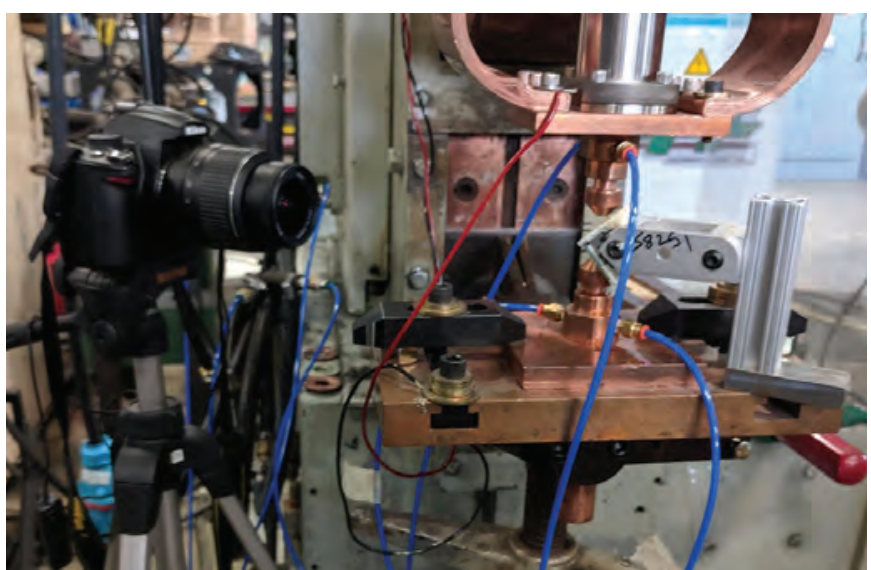

Fig. 2-Configuration of the camera and mirror fixture for collecting electrode face images. Each image from the camera contains both electrode faces.

$\mu \mathrm{F}$ capacitor that can be charged to a peak voltage of $2100 \mathrm{~V}$. This yielded a peak-energy capability of roughly $3 \mathrm{~kJ}$. The power supply included a polarity-switching network and was programmed to reverse the direction of current flow on successive welds. This power supply was integrated with a small welding frame and a 30-kVA transformer setup. The 30-kVA transformer included series and parallel switching as well as an autotransformer. For these studies, the 75:1 transformer turns ratio was used. The frame offered welding forces up to roughly $4.5 \mathrm{kN}$. A fast follow-up was also integrated into the welding frame to ensure electrode-workpiece contact during rapid current cycling. Both systems were subject to monitoring of the welding current. This was done through an Amada Miyachi 326-A weld checker coupled to a Yokogawa recording oscilloscope.

The electrode life testing conducted in this work largely corresponds to that outlined for resistance spot welding sheet metals in Ref. 12. All tests were done using truncated cone electrodes with 5-mm-diameter faces. Testing consisted of first validating welding practices from Part 1 of this work, which yielded conditions just below expulsion. This was done using the $25 \times 100-\mathrm{mm}$ coupons discussed in that work. Then, sequential welding was done on the $25 \times 300$ $\mathrm{mm}$ test strips at a spacing of roughly $25 \mathrm{~mm}$. Each strip contained a preweld on one end to provide consistent shunting. Electrode life tests were documented in a number of ways, including validation through peel testing, metallographic sectioning, and electrode face imaging.

Electrode face imaging was done through a fixture containing two mirrors at a nominal 90-deg angle. The mirrors were in the fixture in such a way that when placed between the electrodes, both electrodes were visible. The fixture located between the electrodes is shown in Fig. 1. The fixture was removable during welding. The images were then collected with a high-resolution single-reflex camera. The orientation of the camera relative to the electrodes and fixture is shown in Fig. 2. Both electrode faces were then captured in one image from the camera.

Through these life tests, peel test validation was done every 50 welds and electrode face imaging was done every 50 welds up to a total count of 250. After that, images were collected every 250 welds. Samples for metallographic exam- 
ination were selected after test completion. For tests, a metallographic sample was collected at the beginning and at $1 / 4$ total life intervals (five samples total).

Samples for metallographic examination were first placed in an epoxy cold mount and polished using standard techniques. Samples were then etched in a solution of $2 \%$ hydrofluoric acid $5 \% \mathrm{H}_{2} \mathrm{O}_{2}$, bal. water solution. This etchant provided good resolution of both the heat-affected zone and nugget sizes. Metallographic assessments were only done on a macroscale, largely to assess variations in weld nugget size during electrode life testing.

\section{Results}

Electrode life testing was done with the aforementioned procedures. Baseline results (button size vs. number of welds) for duplicate tests using the MFDC power supply are shown in Table 1 . Welding conditions again included a 5-mm initial face diameter, 8 -L/min water cooling through the electrodes, 4-kA/40-ms prepulse, 20-kA/80-ms main pulse, and $2.2 \mathrm{kN}$ of applied force. Table 1 provides the measured button size (from peel testing) as a function of the number of welds. The button size presented was again an average of the major and minor diameters. Tests were conducted until the weld size dropped below the minimum condition, as defined in AWS standards (Ref. 12).

The periodic electrode face images taken from the aforementioned replicate 2 test are presented in Fig. 3 . As per the test protocol previously mentioned, images of the electrode faces were provided every 50 welds up to 250 spots. Afterward, data was collected every 250 welds until the end of the test. In these images, the bottom electrode is the cathode $(-)$, and the top electrode is the anode $(+)$. The results show that the lower electrode (cathode) essentially picked up a coating of aluminum throughout the duration of the test. However, by 50 welds, the top electrode (anode) showed the effects of alloying and cavitation. Damage to the top electrode face and subsequent increases in diameter were evident throughout the test. By the end of the test, the top electrode showed a significant increase in diameter com-

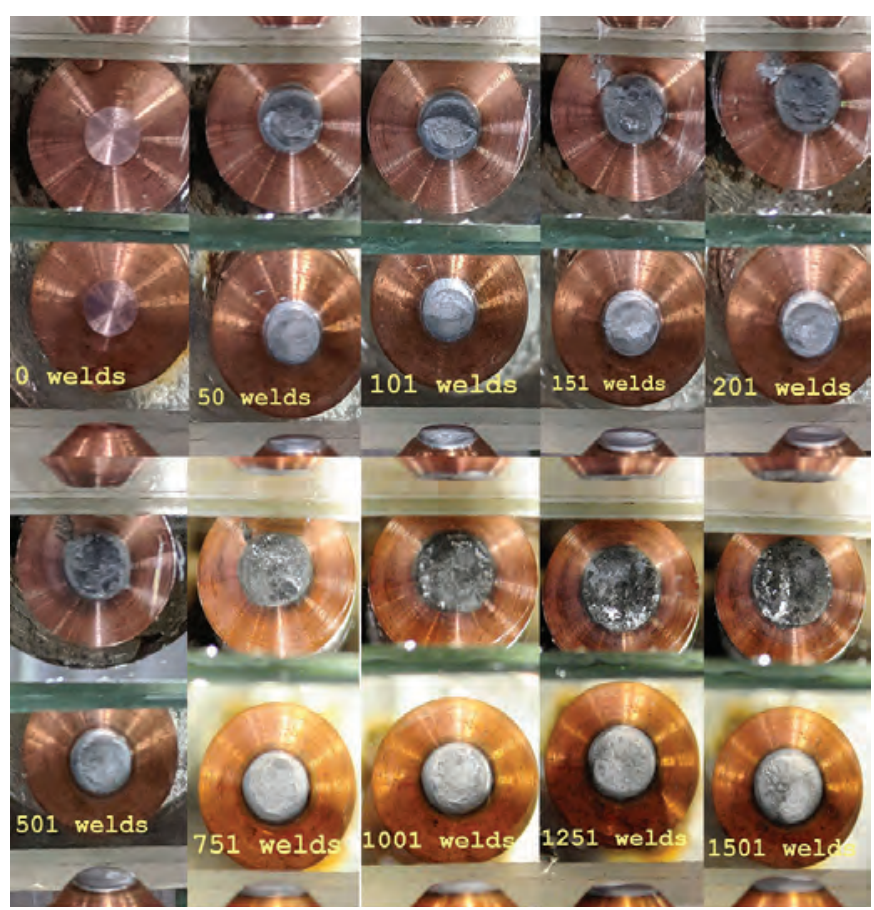

Fig. 3 - Sequential electrode wear during a test using MFDC power. Images were collected every 50 welds up to a total of 250 welds, and then images were collected at 250-weld increments.

pared to that of the bottom.

Measurements of the electrode face diameters were then measured from these images and tabulated as a function of the number of welds. Those results are presented in Table 2. The replicate electrode life and face-growth data are graphically presented in Figs. 4 and 5, respectively. The electrode life plot (Fig. 4) shows the button size as a function of the number of welds throughout the test for both replicates. Also included on this plot is a line representing the minimum button size for the test. Both tests started with a weld size of roughly $5 \mathrm{~mm}$. The test results themselves for the

Table 1-Button Size as a Function of the Number of Welds during Duplicate Electrode Life Testing Using an MFDC Power Supply

First Replicate Test

\begin{tabular}{|c|c|c|c|c|c|c|c|}
\hline $\begin{array}{l}\text { Weld } \\
\text { Number }\end{array}$ & $\begin{array}{c}\text { Average } \\
\text { Button Size (mm) }\end{array}$ & $\begin{array}{l}\text { Weld } \\
\text { Number }\end{array}$ & $\begin{array}{c}\text { Average } \\
\text { Button Size (mm) }\end{array}$ & $\begin{array}{l}\text { Weld } \\
\text { Number }\end{array}$ & $\begin{array}{c}\text { Average } \\
\text { Button Size }(\mathrm{mm})\end{array}$ & $\begin{array}{l}\text { Weld } \\
\text { Number }\end{array}$ & $\begin{array}{c}\text { Average } \\
\text { Button Size (mm) }\end{array}$ \\
\hline 1 & - & 751 & 5 & 1 & 5.1 & 801 & 5.2 \\
\hline 51 & 5.1 & 801 & 4.8 & 51 & 4.8 & 851 & 4.5 \\
\hline 101 & 5 & 851 & 5.1 & 101 & - & 901 & 4.8 \\
\hline 151 & 5 & 901 & 5 & 151 & 4.8 & 951 & 4.5 \\
\hline 200 & 5.7 & 951 & 5.2 & 201 & 5 & 1001 & 5.2 \\
\hline 201 & 5.3 & 1001 & 4.9 & 251 & 4.4 & 1051 & 4.8 \\
\hline 251 & 5.2 & 1051 & 4.9 & 301 & 4.5 & 1101 & 5 \\
\hline 301 & 4.9 & 1101 & 4.7 & 351 & 4.7 & 1151 & 5 \\
\hline 351 & 5 & 1151 & 4.6 & 401 & 5.2 & 1201 & 4.5 \\
\hline 401 & 5 & 1201 & 5.5 & 451 & 4.5 & 1251 & 4.1 \\
\hline 451 & 4.7 & 1251 & 4.5 & 501 & 4.9 & 1301 & 3 \\
\hline 501 & 4.8 & 1301 & 5.1 & 551 & 4.5 & 1351 & 5 \\
\hline 550 & 4.7 & 1351 & 5.3 & 601 & 5 & 1401 & 4.5 \\
\hline 601 & 4.9 & 1401 & 3.6 & 651 & 4.8 & 1451 & 2.3 \\
\hline 651 & 5.1 & 1402 & 0 & 701 & 5 & 1501 & 0 \\
\hline 701 & 5.3 & 1403 & 3.8 & 751 & 5.1 & - & - \\
\hline
\end{tabular}




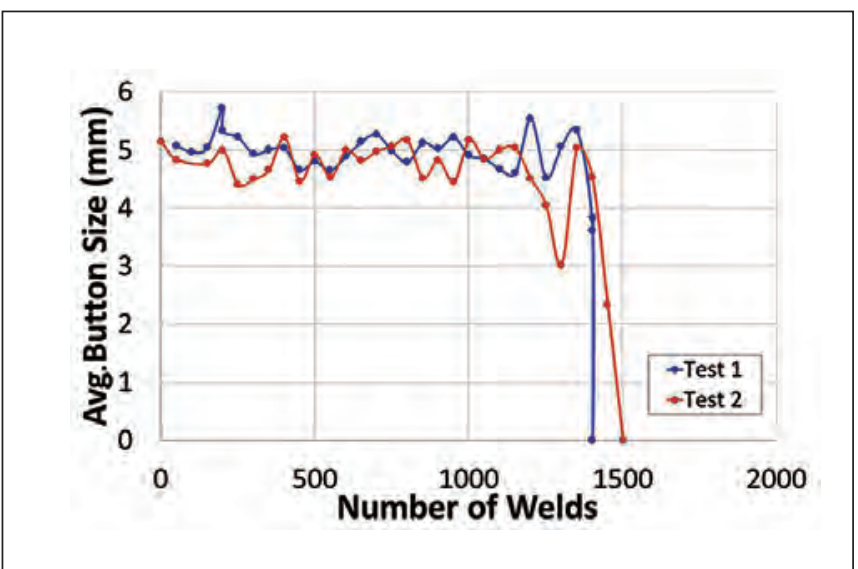

Fig. 4 - Duplicate electrode life tests using the MFDC power supply.

two replicates were quite similar. For up to 1000 welds, the button size was relatively stable, varying roughly by about \pm $0.5 \mathrm{~mm}$. After 1000 welds, both tests showed much larger fluctuations in the nugget size, with total failure by 1500

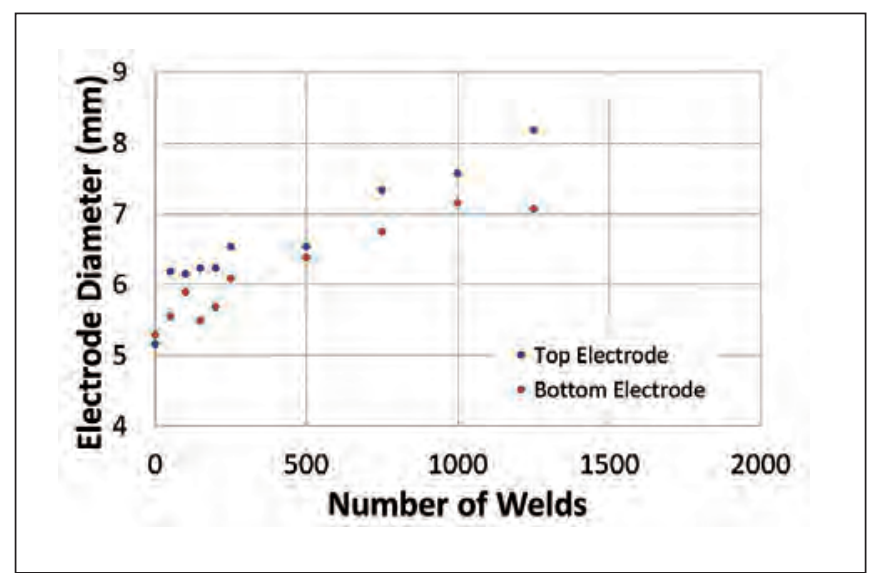

Fig. 5 - Variations in top and bottom electrode face diameters observed during the second MFDC life test.

welds. The weld-face-diameter plot (Fig. 5) showed that both top and bottom electrodes began the test at roughly 5 $\mathrm{mm}$. However, the top electrode quickly expanded to greater than $6 \mathrm{~mm}$ and finished the test with a nominal $8 \mathrm{~mm}$ diam-

Table 2 - Estimated Top and Bottom Electrode Sizes from the Second Replicate Electrode Life Test Using MFDC Current

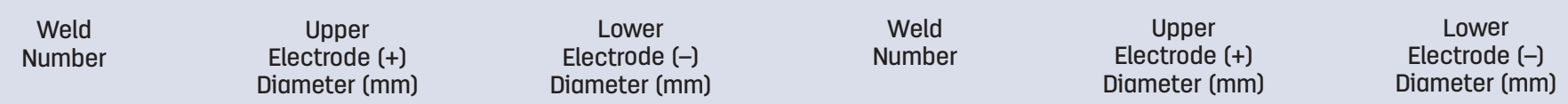

\begin{tabular}{cccccc}
\hline 1 & 5.2 & 5.3 & 251 & 6.5 & 6.1 \\
51 & 6.2 & 5.5 & 501 & 6.5 & 7.3 \\
101 & 6.1 & 5.9 & 751 & 6.4 & 7.6 \\
151 & 6.2 & 5.5 & 1001 & 7.2 & 7.2 \\
201 & 6.2 & 5.7 & 1251 & 7.1 & \\
\hline
\end{tabular}

Table 3 - Button Size as a Function of the Number of Welds during Duplicate Electrode Life Testing Using a CD Power Supply

First Replicate Test

Second Replicate Test

\begin{tabular}{|c|c|c|c|c|c|c|c|}
\hline $\begin{array}{l}\text { Weld } \\
\text { Number }\end{array}$ & $\begin{array}{c}\text { Average } \\
\text { Button Size (mm) }\end{array}$ & $\begin{array}{l}\text { Weld } \\
\text { Number }\end{array}$ & $\begin{array}{c}\text { Average } \\
\text { Button Size (mm) }\end{array}$ & $\begin{array}{l}\text { Weld } \\
\text { Number }\end{array}$ & $\begin{array}{c}\text { Average } \\
\text { Button Size (mm) }\end{array}$ & $\begin{array}{l}\text { Weld } \\
\text { Number }\end{array}$ & $\begin{array}{c}\text { Average } \\
\text { Button Size }(\mathrm{mm})\end{array}$ \\
\hline 1 & 5.4 & 1100 & 5.1 & 1 & 5.2 & 1000 & 5 \\
\hline 50 & 4.9 & 1150 & 4.7 & 50 & 4 & 1050 & 4.4 \\
\hline 150 & 3.8 & 1250 & 4.8 & 99 & 5.3 & 1150 & 4.9 \\
\hline 200 & 4.4 & 1300 & 4.7 & 150 & 2.7 & 1200 & 4.6 \\
\hline 250 & 4.5 & 1350 & 4.8 & 149 & 3.9 & 1250 & 4.4 \\
\hline 450 & 4.8 & 1550 & 4.7 & 350 & 4.4 & 1450 & 4 \\
\hline 500 & 5 & 1600 & 4.8 & 400 & 5.4 & 1500 & 4.5 \\
\hline 550 & 4.9 & 1650 & 4.4 & 450 & 3.9 & 1550 & 4.4 \\
\hline 600 & 4.5 & 1700 & 4.4 & 500 & 4.6 & 1600 & 4.9 \\
\hline 650 & 4.6 & 1750 & 4.5 & 550 & 4.7 & 1650 & 4.7 \\
\hline 700 & 4.7 & 1800 & 4.5 & 600 & 4.8 & 1700 & 4.7 \\
\hline 1000 & 4.5 & - & - & 900 & 4.7 & 1999 & 5 \\
\hline 1050 & 4.6 & - & - & 950 & 4.4 & 2000 & 3.9 \\
\hline
\end{tabular}



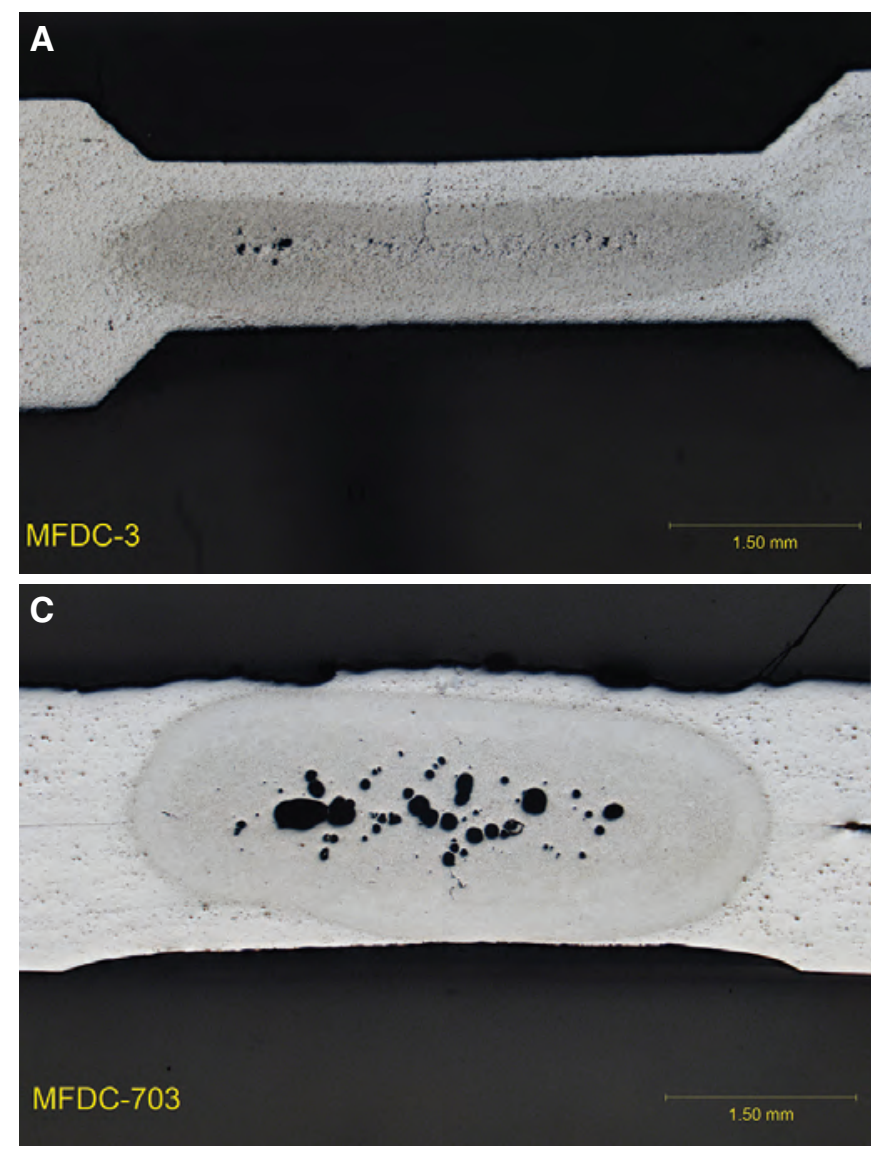

Fig. 6 - Variations in weld nugget morphology occurring during the second replicate electrode life test conducted with MFDC power: $A-3$ welds; $B-353$ welds; $C-703$ welds; D - 950 welds; $E-1454$ welds.

eter. The lower electrode also showed growth during the test. However, the rate of growth was slower and finished the test with a nominal diameter of about $7 \mathrm{~mm}$. In all cases, the upper electrode was larger than the lower one.

Representative metallographic samples taken during the second electrode life test are presented in Fig. 6. These samples were collected at the beginning and nominally at $1 / 4$-life intervals during the test. At the beginning of the test (Fig. $6 \mathrm{~A}$ ), severe indentation was noted. This was probably an artifact of expulsion occurring at that stage. After about 350 welds (Fig. 6B), that indentation was mitigated, and a relatively complete-penetration nugget was the result. Considerable gas porosity was noted in all remaining welds from this test. At 700 welds (Fig. 6C), damage to the electrode-sheet interface on the anode could be seen. This appeared to correspond with reduced levels of electrode indentation on that side. The cross section at 950 welds (Fig. 6D) appeared similar, although the level of internal porosity appeared greater. Finally, at the point of failure (1450 welds, Fig. 6E), excessive porosity and electrode indentation on the cathode side was observed. This appeared to be the result of expulsion, leading to loss of integrity in the weld with subsequent interfacial failure. There was also a bias of the heat-affected zone and nugget toward the anode (upper electrode). This was observed in every cross section from test initiation to failure.

Results from the replicate electrode life tests conducted
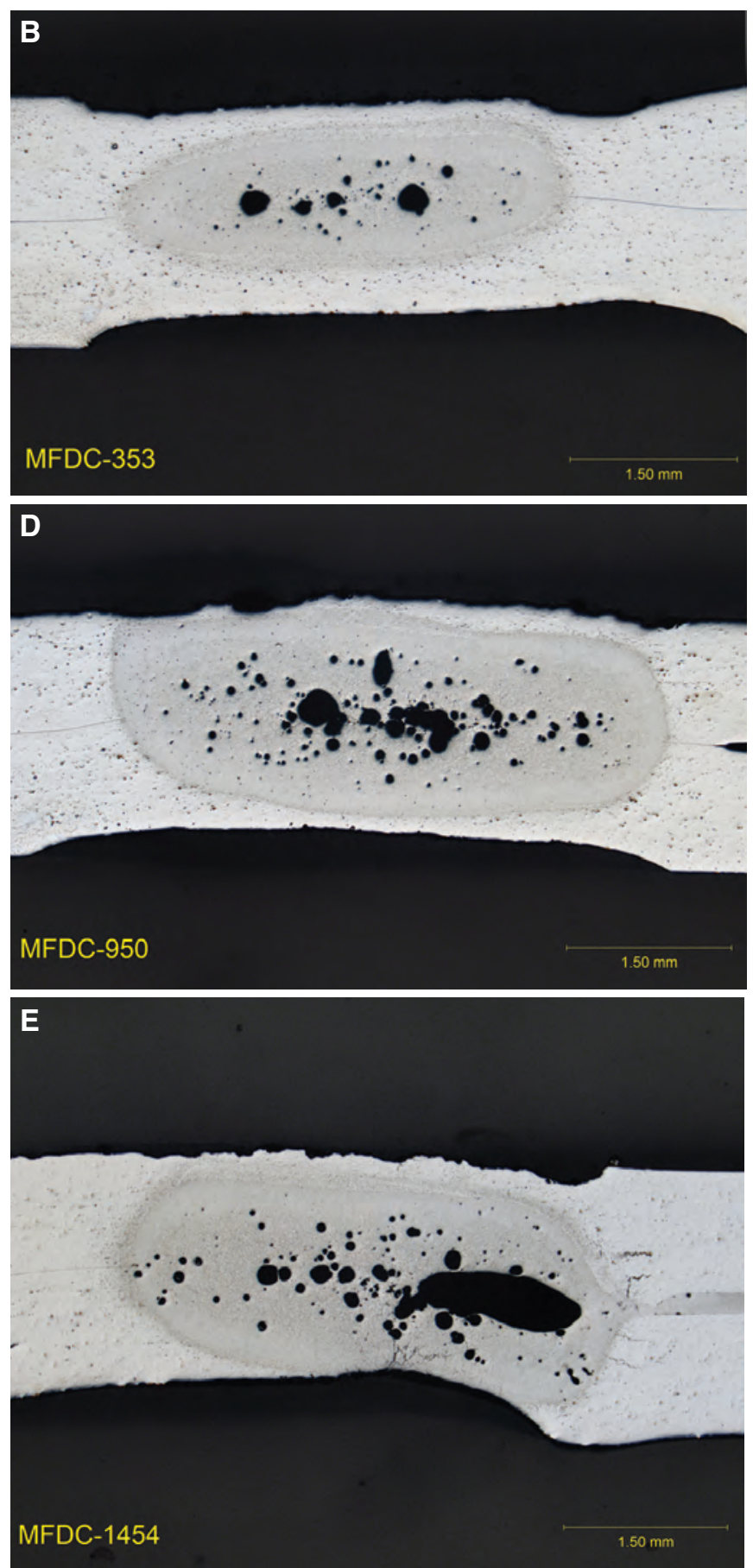

using the CD power supply are provided in Table 3. All tests were conducted using 5-mm-diameter electrodes, a pulse with a $2.5-\mathrm{ms}$ rise time and a 70-kA peak current, a $4.4-\mathrm{kN}$ contact force, and a $8-\mathrm{L} / \mathrm{min}$ water flow through the electrodes. Testing procedures paralleled those for the MFDC electrode life tests. With the exception of a few slightly subsized buttons early in the test (less than 150 welds, button sizes $<3.5 \mathrm{~mm}$ ), both replicate tests ran to completion without failure.

Electrode face images were collected from both the first and second replicate tests. Images from the second test are provided in Fig. 7. As described earlier, images were taken every 50 welds up to 250 welds, then every 250 welds until the end of 


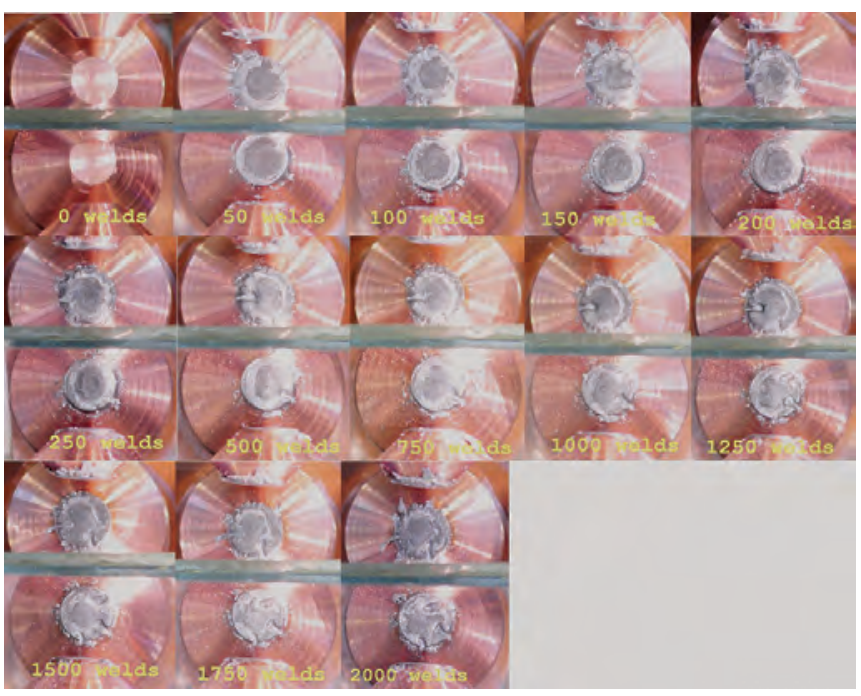

Fig. 7 - Sequential electrode wear during a test using $C D$ power. Images were collected every 50 welds up to a total of 250 welds, and then images were collected at 250-weld increments.

the test. The results suggested that with the first 250 welds, the only change to the electrode face was a buildup of aluminum on the surface. From 500 welds on, that aluminum layer appeared to thicken. With extended wear, the only topographical features appeared to be local variations in the layer thickness. Of note, changes on the top and bottom electrodes appeared to be identical. There was no differential wear characteristic to be observed in this sequence.

Measurements of the electrode face diameters from both the first and second replicate tests are provided in Table 4. For both replicates, the electrode diameters appeared to increase about $1 \mathrm{~mm}$ throughout the duration of the test. There were virtually no differences in the top and bottom electrode diameters for either test replicate. For comparative purposes, an average of the top and bottom electrode diameters is also provided in Table 4.

The replicate electrode life and face-diameter-growth data are graphically provided in Figs. 8 and 9, respectively.

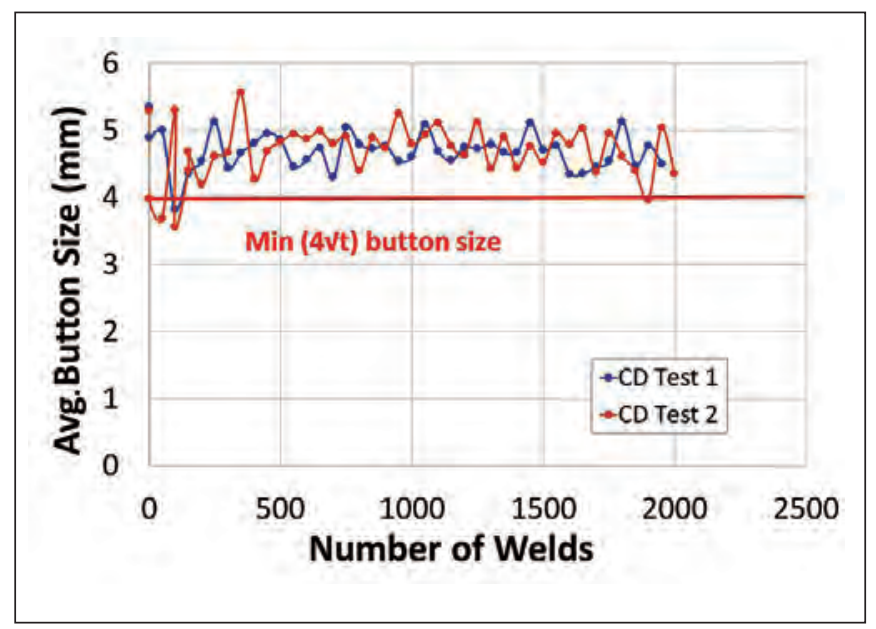

Fig. 8 - Duplicate electrode life tests using the CD power supply.

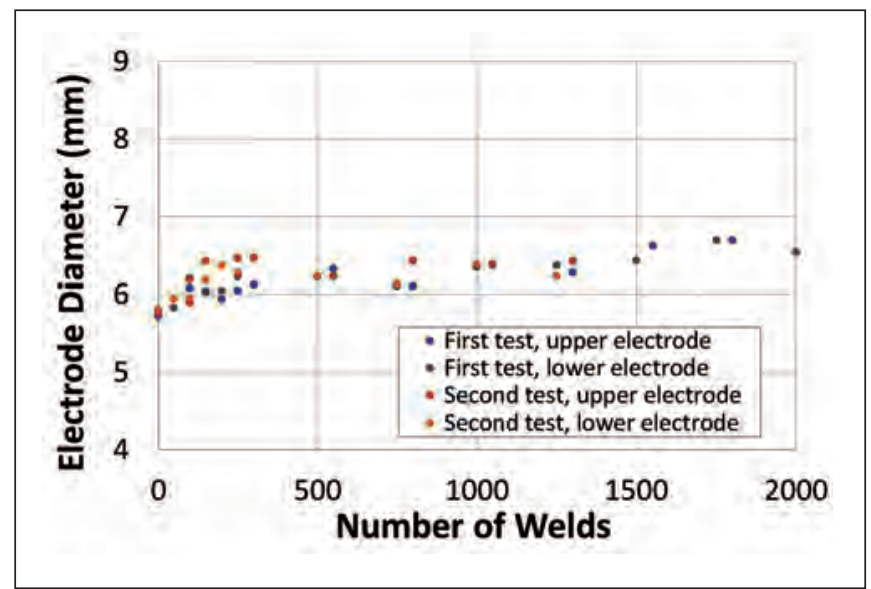

Fig. 9 - Variations in top and bottom electrode face diameters observed during both $C D$ life tests.

The electrode life results (Fig. 8) showed that the measured button size was both stable and reproducible. For both tests, there was some initial loss in button size, but this stabilized

Table 4- Estimated Top and Bottom Electrode Sizes from both Replicate Electrode Life Tests Using CD Power

First Replicate Test

\begin{tabular}{|c|c|c|c|c|c|c|c|}
\hline \multirow[b]{2}{*}{$\begin{array}{l}\text { Weld } \\
\text { Number }\end{array}$} & & \multirow[b]{2}{*}{$\begin{array}{c}\text { Average } \\
\text { Electrode } \\
\text { Diameter (mm) }\end{array}$} & \\
\hline & $\begin{array}{c}\text { Upper } \\
\text { Electrode } \\
\text { Diameter (mm) }\end{array}$ & $\begin{array}{c}\text { Lower } \\
\text { Electrode } \\
\text { Diameter (mm) }\end{array}$ & & $\begin{array}{l}\text { Weld } \\
\text { Number }\end{array}$ & $\begin{array}{c}\text { Upper } \\
\text { Electrode } \\
\text { Diameter (mm) }\end{array}$ & $\begin{array}{c}\text { Lower } \\
\text { Electrode } \\
\text { Diameter }(\mathrm{mm})\end{array}$ & $\begin{array}{c}\text { Average } \\
\text { Electrode } \\
\text { Diameter }(\mathrm{mm})\end{array}$ \\
\hline 100 & 6 & 6.2 & 6.1 & 100 & 6.2 & 5.9 & 6.1 \\
\hline 150 & 5.9 & 6 & 6 & 150 & 6.4 & 6.2 & 6.3 \\
\hline 200 & 6 & 6 & 6 & 200 & 6.5 & 6.4 & 6.4 \\
\hline 750 & 6.1 & 6.1 & 6.1 & 750 & 6.4 & 6.1 & 6.3 \\
\hline 1000 & 6.4 & 6.3 & 6.4 & 1000 & 6.4 & 6.4 & 6.4 \\
\hline 1250 & 6.3 & 6.4 & 6.3 & 1250 & 6.4 & 6.2 & 6.3 \\
\hline 1500 & 6.6 & 6.4 & 6.5 & 1500 & - & - & - \\
\hline 1750 & 6.7 & 6.7 & 6.7 & 1750 & - & - & - \\
\hline 2000 & 6.7 & 6.5 & 6.6 & 2000 & - & - & - \\
\hline
\end{tabular}



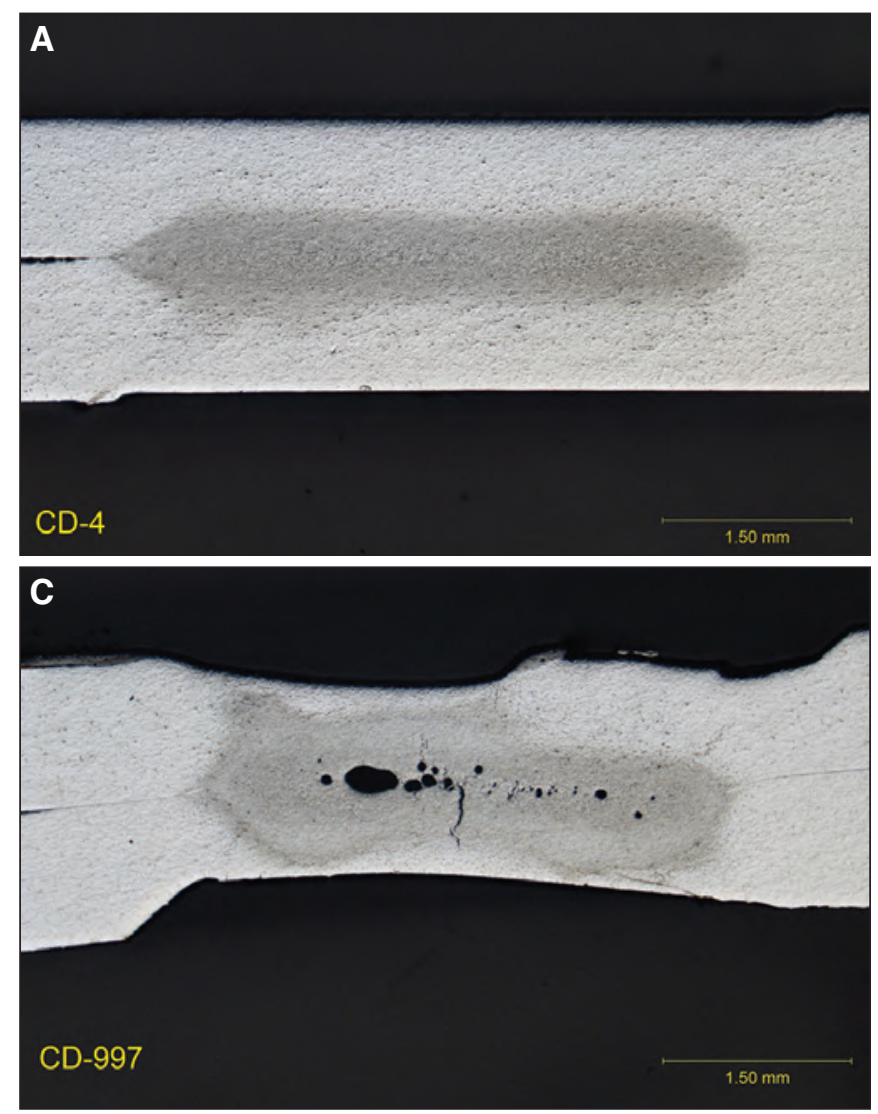

Fig. 10 - Variations in weld nugget morphology occurring during the first replicate electrode life test conducted with CD power: $A-4$ welds; $B-498$ welds; $C-997$ welds; $D-$ 1498 welds; $E-1998$ welds.

by about 200 welds. Following this initial period, the weld size remained consistent within about $\pm 0.25 \mathrm{~mm}$. The electrode face measurements are provided in Fig. 9, which shows the electrode face diameter slightly increased for the first 200 welds then largely stabilized for the remainder of both tests. Of note, the top and bottom electrode-facediameter data for both tests completely overlapped.

Variations in weld nugget morphology throughout the first electrode life test using CD power are provided in Fig. 10. Initial weld nuggets (Fig. 10A) showed very shallow penetration and minimal electrode indentation. Furthermore, any observed nugget porosity was of a very fine scale. After the first 400 welds (Fig. 10B), there was clearly more heat generation, showing greater nugget penetration and indentation. Notably, the widest area of the nugget was at the faying surface, suggesting the dominance of sheet-to-sheet interfacial heating. Nugget penetration increased to roughly $30 \%$, and there was gas-related porosity along the bond line. By 1000 welds (Fig. 10C), there was clearly some topography to the electrode faces based on the observed nonuniform indentation. The nugget itself, however, was nearly identical to the one seen at 500 welds. Interestingly, the nuggets at 1500 and 2000 welds (Fig. 10D, E) were nearly identical to those seen at 500 and 1000 welds. There was clearly some variation in the electrode surfaces (as evidenced by the topography of the indented surface), but these seemed to have little influence on the resulting nugget. These observations were consis-
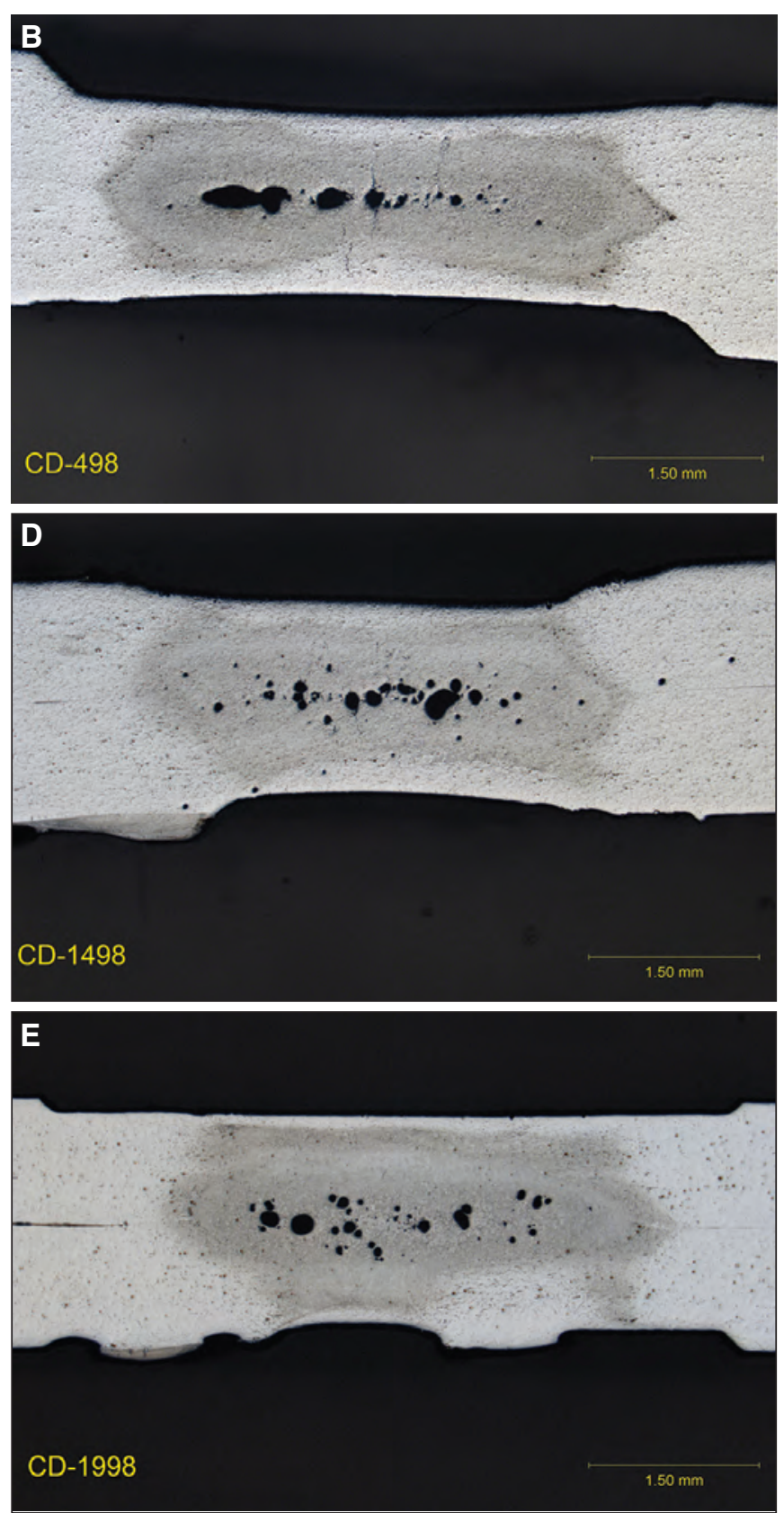

tent with the button pull results described earlier.

Based on the results presented thus far, one additional electrode life test was conducted using CD power. This test was done without cooling water supplied to the electrodes. Water cooling of the electrodes is not often recommended for CD welding (Ref. 13). However, for conventional spot welding, a lack of cooling water allows the electrodes to heat, significantly reducing life (Ref. 14). To investigate this, a single limited-duration electrode life test without cooling water was conducted using the $\mathrm{CD}$ power supply. The test itself was limited to 500 welds, which was largely intended to provide some initial insights on the influence of cooling water for CD-based resistance spot welding of aluminum sheet. The electrode life test itself paralleled those previously described. The test was done under conditions of a 5-mm electrode diameter, 2.5-ms rise time, 70-kA peak current pulse, and welding force of 4.4 $\mathrm{kN}$. The results of this abbreviated test are provided in Table 5 . 


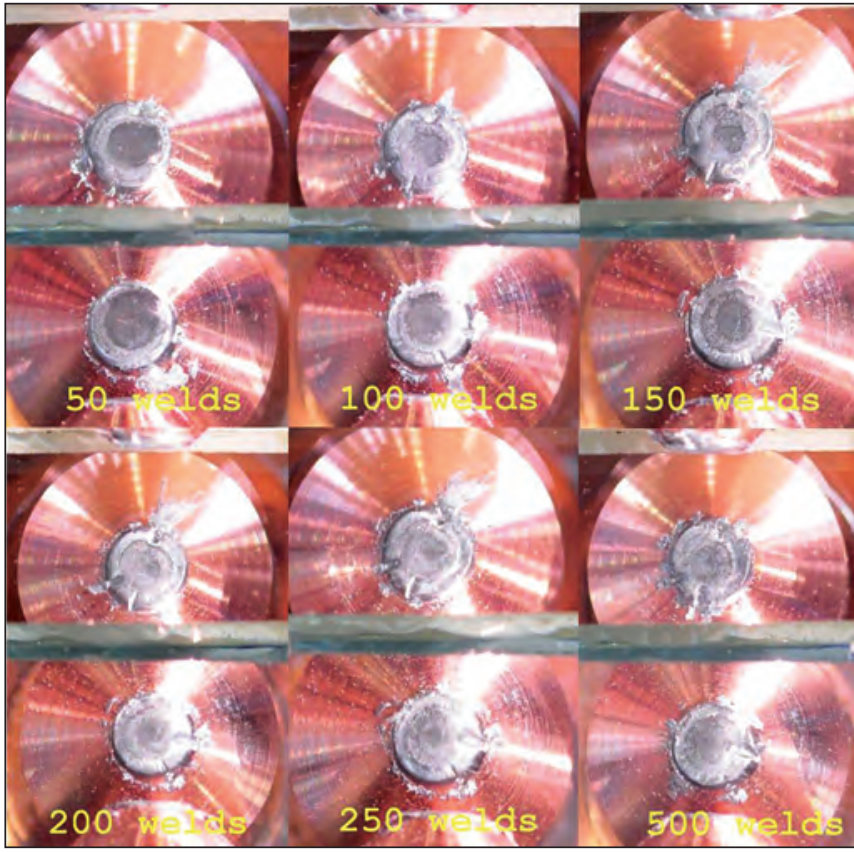

Fig. 11 - Sequential electrode wear during a test using $C D$ power without water cooling. Images were collected every 50 welds up to a total of 250 welds, and then images were collected at 250-weld increments. The test was limited to 500 welds.

As can be seen, the button size was relatively invariant over the 500 welds of electrode wear. The corresponding images of the electrode faces are provided in Fig. 11. Only six images are presented with 50-weld increments up to 250 along with a final image at the end of the test (500 welds). The appearance of these faces closely parallelled those seen for the CD welding life test with water. The electrode faces quickly became coated with aluminum. At 150 welds, there were some indications of local variations in coating thickness, but there were no other changes up to the end of the test. Face-diameter measurements from each of these images are also provided in Table 4.

The data provided in Table 4 for the average button and electrode face diameter are superimposed over the two replicates of test data for welding with water cooling in Figs. 12 and 13 (respectively). Both figures show that the data from the $C D$ power test without water completely overlapped those where active cooling was applied. Button-size measurements showed that the no-water-cooling data was within the scatter band of the two replicate tests. Of interest, there was no apparent drop in the button size early in the test, as seen with the watercooled trials. Not surprisingly, the variations in the electrode face size (Fig. 13) showed similar trends. While the change in the electrode face size during the no-water-cooling test was small (5.6 to $5.8 \mathrm{~mm}$ ), it appeared to follow within the scatter band of the previous data. These tests suggested that there is no apparent detriment to electrode life behavior from eliminating water cooling when employing $C D$ welding.

\section{Discussion}

As described in Part 1 of this work (Ref. 1), CD-based power offers significant advantages for spot welding aluminum sheet. For current range behavior and joint mechanical properties, the implicit short weld times were found to be advantageous. In that companion effort, process waveforms for representative $C D$ and MFDC welds were compared. The CD current pulses used were roughly $10 \%$ of that for conventional MFDC welding. This implied both improved interaction with available contact resistances as well as a reduction of heat penetration (into both the aluminum sheet and copper electrode) of about $75 \%$.

The second feature associated with the MFDC vs. CD waveforms used was polarity switching. It is well established that the inherent differences in electrode life between AC and MFDC systems are associated with polarity and the Peltier effect (Refs. 3, 6). The Peltier effect is associated with preferential heating of one electrode and cooling of the other based on contact thermoelectric voltages either opposing or assisting the applied current (Ref. 15). During AC welding, polarity switches every 16 to $20 \mathrm{~ms}$, balancing these heating effects between the electrodes. For MFDC welding, the preferential heating is maintained at one electrode, which causes accelerated wear. Polarity-switched CD welding (with a nominal 10-ms pulse width) presumably offers a similar balance to the electrodes.

Electrode life tests using MFDC power had results similar to those seen with other authors (Refs. 8, 12,13), showing dissimilar electrode wear with accelerated damage to the anode.

Table 5 - Button Size as well as Estimated Top, Bottom, and Average Electrode Sizes from the Limited Test Using CD Power without Water Cooling

\begin{tabular}{|c|c|c|c|c|}
\hline $\begin{array}{l}\text { Weld } \\
\text { Number }\end{array}$ & $\begin{array}{c}\text { Average } \\
\text { Button } \\
\text { Size }(\mathrm{mm})\end{array}$ & $\begin{array}{c}\text { Upper } \\
\text { Electrode } \\
\text { Diameter }(\mathrm{mm})\end{array}$ & $\begin{array}{c}\text { Lower } \\
\text { Electrode } \\
\text { Diameter }(\mathrm{mm})\end{array}$ & $\begin{array}{c}\text { Average } \\
\text { Electrode } \\
\text { Diameter }(\mathrm{mm})\end{array}$ \\
\hline 1 & 5.3 & - & - & - \\
\hline 50 & 4.8 & 5.6 & 5.6 & 5.6 \\
\hline 100 & 5 & 5.7 & 5.6 & 5.6 \\
\hline 150 & 4.8 & 5.8 & 5.8 & 5.8 \\
\hline 200 & 4.8 & 5.8 & 5.8 & 5.8 \\
\hline 250 & 5 & 5.9 & 5.8 & 5.8 \\
\hline 300 & 4.7 & - & - & - \\
\hline 350 & 4.6 & - & - & - \\
\hline 400 & 4.9 & - & - & - \\
\hline 450 & 5 & - & - & - \\
\hline 455 & - & 5.8 & 5.7 & 5.8 \\
\hline 500 & 4.7 & 5.9 & 5.7 & 5.8 \\
\hline
\end{tabular}




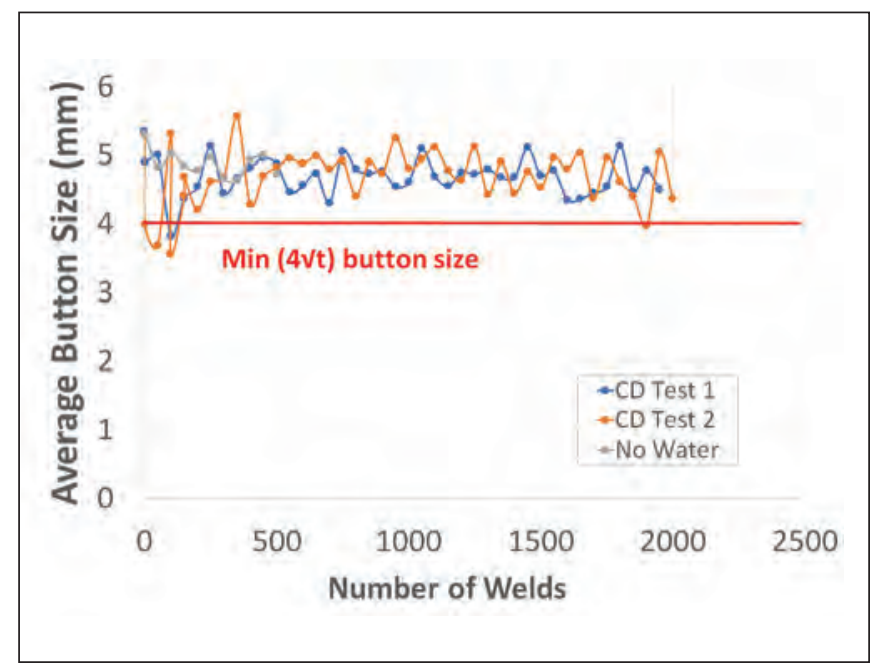

Fig. 12 - Electrode life results for the $C D$ power no-water test superimposed on the data where active cooling is used.

In these trials, life was limited to about 1400 welds. As mentioned previously, this behavior is widely attributed to the Peltier effect. Of interest, even though the anode wears preferentially, the cathode also showed an increase in diameter of roughly $60 \%$ (5-7 $\mathrm{mm}$ ). The $\mathrm{CD}$ electrode life tests did not show any differential wear between the two electrodes. Switching polarity from weld to weld had the effect of balancing the wear between the two electrodes. The resulting life tests ran to targeted completion ( 2000 welds). The electrodes over this testing period showed only a roughly $15 \%$ increase in diameter (5.5-6.5 mm). This showed a marked reduction in wear compared even to the cathode (subject to Peltier cooling) in the MFDC tests. This response was associated with the lack of heat soak from the weld into the copper electrode resulting from the narrow $C D$ pulse. As previously noted, heat-soak depths into the copper electrode during $C D$ welding were less than $1 / 3$ of that for the MFDC welding process examined. The influence of the thermal profile in the electrode and its influence on electrode life for galvanized steels has been described elsewhere (Refs. 16, 17). While the temperature ranges experienced by the electrodes are decidedly different (much lower when welding aluminum sheet), local heat content still plays a role. Here, it appears that the thermal cycles at the electrodesheet interface were insufficient to markedly contribute to electrode wear.

It was noted on both electrode life tests done with the polarity-switching $C D$ power supply that a slight reduction in the measured button size was observed over the first 200 welds. This corresponds to the number of welds required for stabilization of the electrode face size in these tests. This phenomenon is related to a break-in period for the electrodes during these tests. Break-in periods (numbers of welds on the electrodes) are commonly used to provide stable results during this type of testing (Ref. 12). During break-in, the electrodesheet contact resistances drop (as changes in the face geometry occur) then rise as substrate materials begin to adhere. For this study, tests were begun with newly machined electrodes, leading to the observed phenomenon.

This lack of significant electrode wear on conventional electrode life tests using $C D$ power led to one additional trial with-

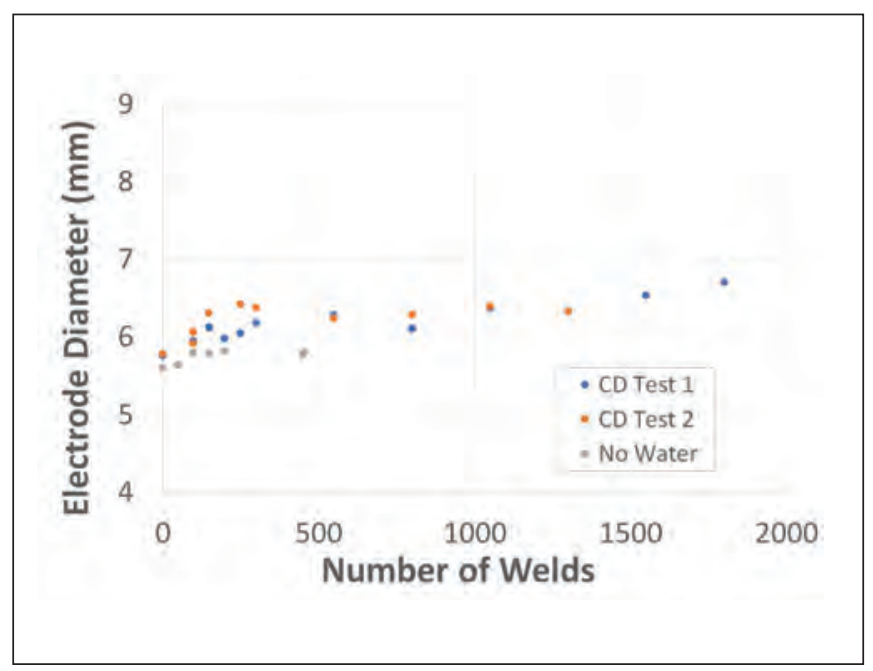

Fig. 13 - Variations in average electrode face diameters with and without water cooling during life testing.

out cooling water. It is well understood that the role of cooling water is to remove heat from the electrode in between welds (Refs. 6, 18). Reducing the total heat content by minimizing the heating time then reduces the thermal load on the system. However, for $\mathrm{CD}$ welding, water cooling of the electrode is often avoided (Ref. 13). The additional electrode life test conducted here also suggests that water cooling is not required. In this test, button- and electrode-face-diameter variations exactly paralleled what was seen when water cooling was employed. One noticeable difference was the lack of a drop in the measured button size at the beginning of the test. Additionally, electrode size was relatively consistent throughout the test. These two observations suggest a change in the electrode break-in behavior for tests without cooling water, but such conclusions require further research.

\section{Conclusions}

The work described here is the second part in an effort to investigate the use of polarity-switching capacitor power supplies for the resistance spot welding of aluminum. These power supplies are of interest for both their narrow current-pulse widths and inherent polarity switching. The first part of this work was published separately (Ref. 1) and describes differences in process robustness between aluminum spot welds made with MFDC and $C D$ power. This second part of the work addresses electrode life testing. In Part 2, duplicate electrode life tests were run using both types of power. Those conducted with polarity-switching $C D$ power showed longer total lives, reduced electrode-face growth rates, and balanced wear. Lives consistently exceeded the 2000 weld limit of the test. Additional testing suggested that similar results could be obtained without the use of the cooling water common for conventional-type resistance spot welding systems. Individual conclusions from this second part of the work are described below:

1. Electrode lives for the MFDC tests were characterized by differential electrode wear and premature failure. Consistent with other authors, MFDC welding resulted in accelerated wear on the anode electrode. 
2. The cathode on the electrode life test using MFDC power also showed an increase in the face diameter. The cathode during the MFDC life tests increased in diameter by roughly $60 \%$. This was related to the longer thermal cycles used for MFDC welding, which increased the time at temperature for interaction between the aluminum and the copper.

3. Both anode and cathode electrodes demonstrated wear during testing. Electrode wear was simply exaggerated by the difference in Peltier voltage polarity.

4. Electrodes during the polarity-switching CD electrode life tests wore uniformly. Polarity switching balanced electrode wear and minimized interactions between the aluminum and copper.

5. Improvements in electrode life when using polarityswitching $C D$ power are associated with both Peltier effects and short heat-soak times. Polarity switching was seen to balance preferential heating associated with Peltier effects between the electrodes. Narrow pulse widths were seen to minimize heat penetration into the electrodes. Both contributed to the improved electrode life performance observed.

6. Similar electrode life results appear achievable without the use of cooling water. It appears the heat conducted into the electrodes during CD welding was minimal enough to be dissipated without cooling water.

\section{References}

1. Gould, J. E., Lindamood, L., Malpica, J., Lester, P., and Zhu, D. 2021. Capacitor discharge spot welding of aluminum, Part 1: Weldability assessments. Welding Journal 100(10): 309-s to 322-s. DOI: $10.29391 / 2021.100 .028$

2. Taub, A., De Moor, E., Luo, A., Matlock, D. K., Speer, J. G., and Vaidya, U. 2019. Materials for automotive lightweighting. Annual Review of Materials Research 49: 327-359. DOI: 10.1146/ annurev-matsci-070218-010134

3. Gould, J. E. 2012. Joining aluminum sheet in the automotive industry - A 30 year history. Welding Journal 91(1): 23-s to 43-s.

4. Jennings, J., and Gould, J. E. 2008. A new road for automotive architectures. Welding Journal 87(10): 36-30.

5. Dickinson, D. W. 1981. Welding in the automotive industry. Report 81-5. Committee of Sheet Steel Producers.

6. Fukumoto, S., et al. 2003. Effects of electrode degradation on electrode life in resistance spot welding of aluminum Alloy 5182. Welding Journal 82(11): 307-s to 312-s.
7. Peng, J., Fukumoto, S., Brown, L., and Zhou, N. 2004. Image analysis of electrode degradation in resistance spot welding of aluminium. Science and Technology of Welding and Joining 9(4): 331-336. DOI: $10.1179 / 136217104225012256$

8. Mikhalapov, G. S., and Falls, T. F. 1942. Structural and metallurgical properties of condenser discharge spot welds. Welding Journal 21(4): 223-229.

9. Hess, W. F., Wyant, R. A., and Winsor, F. J. 1946. The spot welding of ten aluminum alloys in the 0.040 -inch gage. Welding Journal 25(8): 467-s to 484-s.

10. Gould, J. E., and Lewis, S. 2021. Capacitive discharge welding system. U.S. Patent 10,967,454 B2

11. Gould, J. E., and Lewis, S. 2016. Development of an open architecture capacitive discharge welding system. Sheet Metal Welding Conference XVII, Paper 3B-5. Detroit, Mich.: AWS Detroit Section.

12. AWS D8.9M:2012, Test Methods for Evaluating the Resistance Spot Welding Behavior of Automotive Sheet Steel Materials. Miami, Fla.: American Welding Society.

13. Kondensatorentladungsschweißen-Grundlagen. 2016. Verfahren und Technik, Merkblatt DVS, 2911.

14. Hirsch, R. 1996. Influence of water temperature and flow on electrode life. Sheet Metal Welding Conference VIII, Paper E3. Detroit, Mich.: AWS Detroit Section.

15. Hasir, M. 1984. A study of the peltier effect in the resistance spot welding of very thin-gage sheet electroplated with tin using tungsten insert electrodes. Schweissen Schneiden 36(3): 116-121.

16. Gould, J. E., and Peterson, W. 2008. Analytical modelling of electrode wear occurring during resistance spot welding. Science and Technology of Welding and Joining 13(3): 248-253. DOI: 10.1179/174329308X271724

17. Li, W. 2005. Modeling and on-line estimation of electrode wear in resistance spot welding. Journal of Manufacturing Science and Engineering 127(4): 709-717. DOI: 10.1115/1.2034516

18. Rao, Z. H., Liao, S. M., Tsai, H. L., Wang, P. C., and Stevenson, R. 2009. Mathematical modeling of electrode cooling in resistance spot welding. Welding Journal 88(5): 111-s to 119-s.

JERRY E. GOULD (jgould@ewi.org) and LINDSEY LINDAMOOD are with EWI, Columbus, Ohio. JULIO MALPICA, PATRICK LESTER, and DEWEI ZHU are with Novelis Global Technology Center, Atlanta, Ga. 